\title{
The Epidemic in the Archives: A Layman's Guide to Cellulose Acetate Lamination
}

Most RBM readers are archivists and rare-book librarians. As a preservation professional, what would you do if you knew that there were certain documents and manuscripts in your collection that were deteriorating at a faster rate than others? What if the only way of treating those items to stop or significantly slow the deterioration was difficult, time consuming, expensive, and could only be performed by trained conservators? What if there were hundreds, thousands, or even millions of such documents and manuscripts within your collection and if nothing was done they would eventually deteriorate so as to become unsalvageable? What if some of these items in your collection might already be too far gone to be saved?

Unfortunately, this is the case if your collection has documents or books that were conserved using the cellulose acetate lamination process. Between the 1930s and the 1980s cellulose acetate lamination was a common treatment considered a safe and advisable measure for document conservation. In time, however, archivists and conservators began to notice and acknowledge its destructive effects and after 40 years, they finally put an end to the practice. By then, however, the damage was done. Today, many archives and special collections are burdened with these laminated items. As they deteriorate, we lose the historical documents and other resources that our profession is dedicated to trying to preserve. Because of this impending crisis it is in everyone's best interest that we find a solution before many of these documents are lost forever-but is there one?

Basically, lamination involved sandwiching a document between two superheated sheets of cellulose acetate and pressing it so as to attach or melt the plastic to the document surface with the concept being that the lamination strengthened and protected the document. The practice began after a 1934 report by the National Bureau of Standards recommended cellulose acetate lamination as a modern and inexpensive replacement for earlier silk and Japanese-paper or -tissue lamination procedures. $^{1}$

1. B. W. Scribner, "Preservation of Newspaper Records," National Bureau of Standards Miscellaneous Publication 145 (1934): 1-10.

๑) 2017 by Eddie Woodward (CC BY-NC [https://creativecommons.org/licenses/by-nc/4.0/]). 


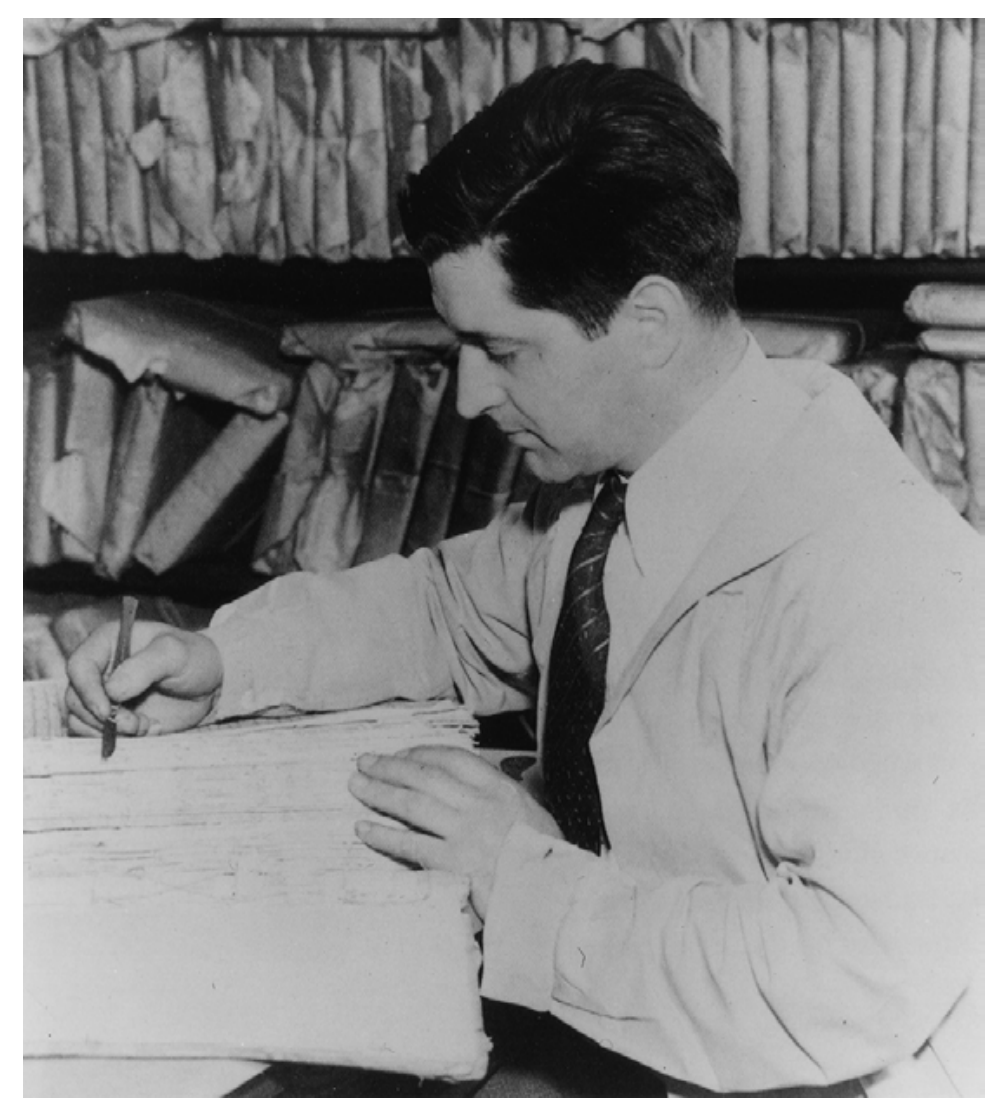

ILLUSTRATION 1. William J. Barrow at work in his restoration shop at the Virginia State Library. (Library of Virginia)

One of the early advocates for this process was William J. Barrow, who operated his conservation shop out of the Virginia State Library (now the Library of Virginia). In the chapter entitled, "It's Not Working Out," in his book, Double Fold: Libraries and the Assault on Paper, Nicholson Baker described the laminating process used by Barrow like this:

You take a fragile manuscript, or the disbound leaf of a book or newspaper, you layer it between two sheets of plastic, with some tissue included for strength and some chemicals to counteract acidity, and heat this sandwich up. Then you run it through a pair of rollers at great pressure until the plastic fuses permanently to the paper. It's similar to what happens to new drivers' licenses at the Department of Motor Vehicles, but instead of wallet IDs, Barrow was operating on eighteenth-century historical documents. 
Baker clearly was not a fan of Barrow's cellulose acetate lamination process. ${ }^{2}$

Today it is difficult to imagine that the process of taking sheets of transparent plastic (or rather thermoplastic) and melting them on to irreplaceable historical documents was ever thought to be a good idea, but it was. During the era when it was considered a preservation standard, institutions laminated documents with gusto. Complicating the problem today is the fact that all along the way, the lamination process was constantly changing.

\section{The Disease}

During its heyday, the process of cellulose acetate lamination was ever evolving and few thought it wise to wait for the process to be ironed out or standardized before they began imposing lamination as a conservation measure. In short, the process in which a document was laminated in the 1930s was different from the process in the 1980s, and it evolved every year in between. As a result, the decomposition of laminated documents can vary because of the technology, process, or material in use during the time when the documents were laminated; the unique qualities of a specific manuscript or printed sheet in terms of its composition and history; and who was doing the laminating. The environmental conditions in which the documents were stored since they were treated also contributes to the rate of deterioration. ${ }^{3}$

Cellulose acetate lamination in the 1930s continued a tradition of strengthening documents that began first with silk, in the latter part of the $19^{\text {th }}$ century. The process of laminating with silk, or "silking" continued, albeit limitedly, into the mid-twentieth century. Silk was later supplanted by cellulose tissue, which was also used to "strengthen" documents as a conservation technique. These conservation techniques fell out of favor because silking was expensive, laminating with tissue made the documents difficult to read, and both had a limited life expectancy of 20 to 30 years. ${ }^{4}$

After the NBS signed off on cellulose acetate lamination as a paper conservation treatment in 1934, the National Archives began conserving documents with their own hydraulic laminator. The process appeared to have gained more steam in the late 1930s with William J. Barrow's creation of a roller-type machine that would heat and press the laminate film or foil to the document. This new process used

2. Nicholson Baker, Double Fold: Libraries and the Assault on Paper (New York: Random House, 2001): 148.

3. Marit Munson, editor, with contributions by Jayne Girod Holt, et al. Guidelines for the Care of Works on Paper with Cellulose Acetate Lamination (Washington, DC: Smithsonian Institution, Anthropology Conservation Laboratory, n. d.), accessed March 9, 2017, http: / anthropology.si.edu/ conservation/ lamination/; Susan Page, "Cellulose Acetate Lamination at the National Archives Part 1: The Louisiana Purchase Documents, a Case Study,” Book and Paper Group Annual 22 (2003): 55.

4. W. J. Barrow, "Deacidification and Lamination of Deteriorated Documents, 1938-1963," American Archivist 28, no. 2 (April 1965): 285. 


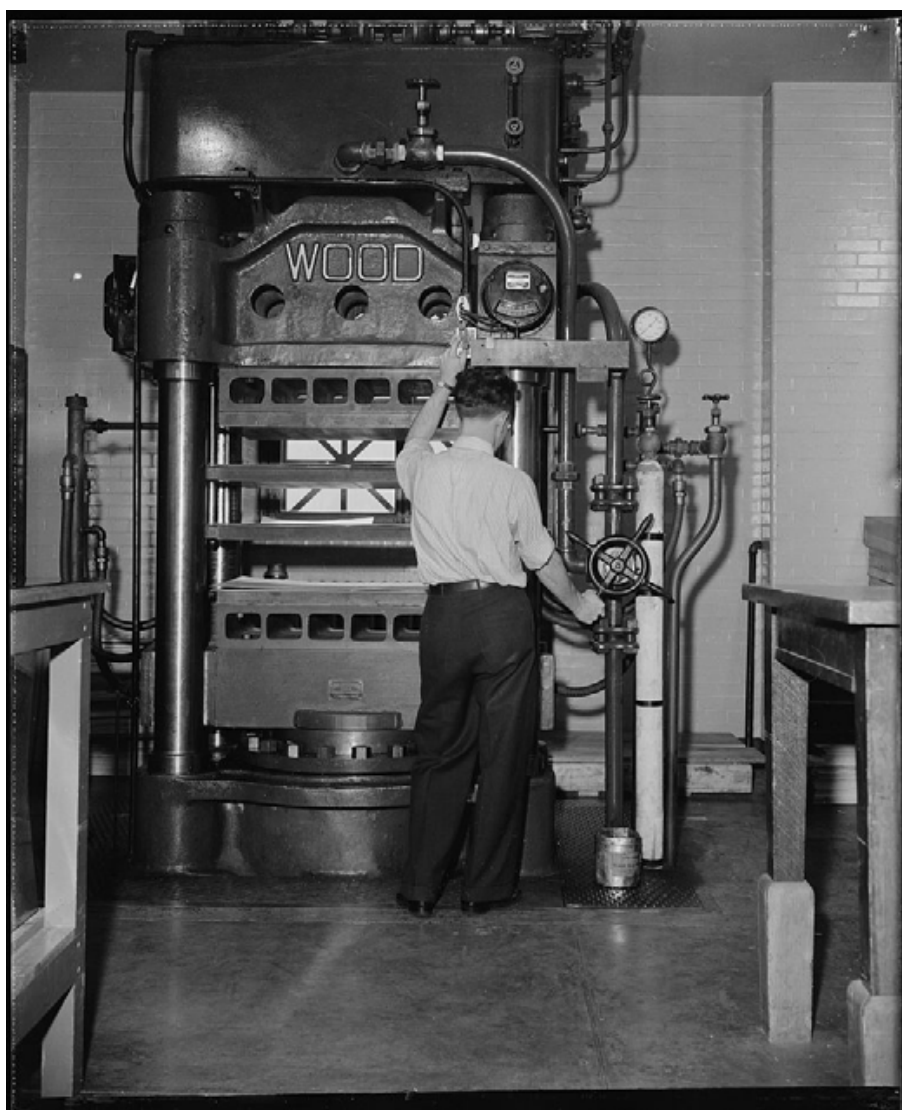

ILLUSTRATION 2. "National Archives. Washington, D.C., Nov. 22 [1939]. In the powerful press, the sheets of acetate, under heat and pressure 'melt' into the pores of the paper and adhere to each other as well...." (Harris \& Ewing collection, Library of Congress Prints \& Photographs Division)

"special precision-built equipment with controlled heat and pressure." Barrow's procedure, with cellulose acetate film only, did not strengthen the documents as much as desired. As a result, Barrow began adding a layer of "strong, well-purified tissue" on top of each side of the laminate film to reinforce the documents. Barrow described it as a sandwich: Tissue/Film/Paper to be restored/Film/Tissue. ${ }^{5}$

Additionally, the early process did not include the deacidification of the document that was being laminated in the film. Frazer G. Poole would later write that

5. Scribner, "Preservation of Newspaper," 1-10; Molly McGath, Sonja Jordan-Mowery, Mark Pollei, Steven Heslip, and John Baty, "Cellulose Acetate Lamination: A Literature Review and Survey of PaperBased Collections in the United States," Restaurator: International Journal for the Preservation of Library and Archival Material 36, no. 4 (2015): 338; Barrow, "Deacidification and Lamination," 286; Ray O. Hummel, Jr. and W. J. Barrow, "Lamination and Other Methods of Restoration," Library Trends 4 (January 1956): 264; John W. Baty, Crystal L. Maitland, William Minter, Martin A. Hubbe, and Sonja K. Jordan-Mowery, "Deacidification for Conservation," BioResources 5, no. 3 (2010): 2002. 


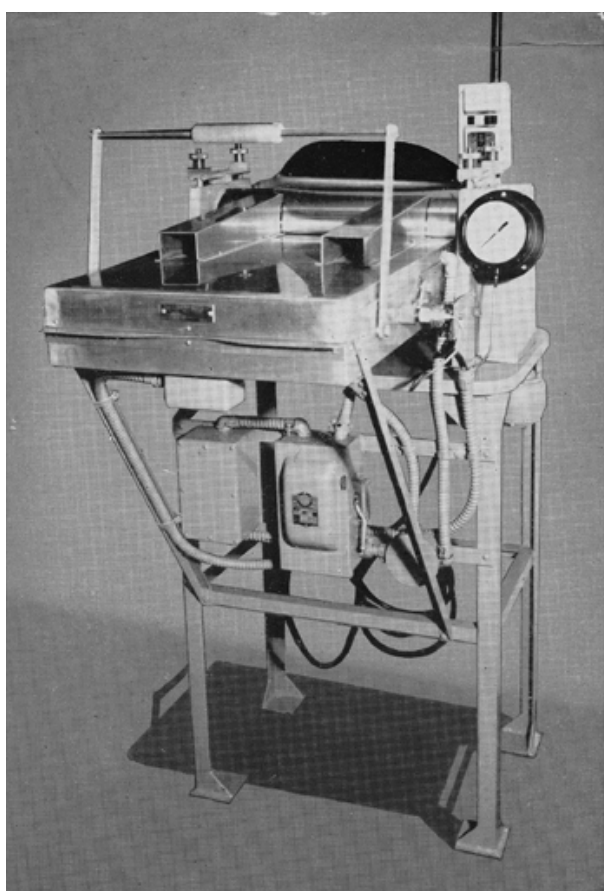

ILLUSTRATION 3. The Barrow patented roller laminator, pictured in W.J. Barrow, Procedures and Equipment Used in the Barrow Method of Restoring Manuscripts and Documents (Richmond, Va.: W.J. Barrow, 1952). (Library of Virginia) "lamination without deacidification and alkaline buffering is nearly worthless as an archival preservation technique.” In 1941 Barrow began incorporating a deacidification process prior to lamination. This component proved to be critical because the acidic paper degraded faster from the heat generated during the laminating process, and more significantly, the laminate seals the acids into the paper with no way to off-gas or ventilate, thereby hastening the document's deterioration. Contributing to the acidic qualities of the paper were the writing inks that were often used in the older documents, particularly iron gall ink which was often highly acidic. To complicate matters even more, the cellulose acetate films themselves were made from woodpulp, making them acidic also, and in the 1940s Barrow began deacidify-

ing the laminate films. Barrow eventually got to a point in the process where he was trying to deacidify the cellulose acetate film, the tissue added for strength, and the document to be conserved, all at one time by, "pickling the laminates between sheets wet with a concentrated solution of magnesium bicarbonate" to neutralize the acidity in all three components. ${ }^{6}$

At some point in the process, plasticizers were added to the cellulose acetate film to give it strength and flexibility; more importantly the added plasticizer lowered the temperature necessary to soften the laminate. Not long after, however, Barrow noted that the plasticizer was evaporating, leaving the laminate less flexible and more brittle. In a test conducted by Barrow in 1962 he noted that because the plasticizer

6. James L. Gear, "Lamination After 30 Years: Record and Prospect," American Archivist 28, no. 2 (April 1965): 294, 296; Barrow, "Deacidification and Lamination,” 286-287; Poole would later write that Barrow's deacidification methods were inadequate. Poole, "Current Lamination Policies," 157; Preservation: Accelerated Aging of Paper: Can It Really Foretell the Permanent of Paper: Aging of Paper Sealed Within Polyester Film (Washington, DC: Library of Congress, May 2, 2014), https: / /www.loc.gov/preservation/ resources/rt/AcceleratedAging.pdf. 
made up as much as one-third of the cellulose acetate foil used, the evaporation of the added plasticizer could be measured in the physical weight loss of the conserved documents. Because of the different material types and quality of the plasticizers being used the test also showed that the laminates lost the plasticizer at different rates. It is thought that one of the main reasons that the cellulose acetate lamination process was deemed unstable is because of the inconsistencies introduced by the addition of the plasticizers and the various types of plasticizers that were used. ${ }^{7}$

As he continued to refine the process, Barrow was routinely going back and delaminating documents in order to re-laminate them in accordance with the newer processes. The delamination process further weakened the documents that he was trying to strengthen, before he laminated them again. By 1959 the continued relaminating of previously laminated documents was beginning to cause something of a rift between Barrow and Randolph Church, the State Librarian and the director of the Virginia State Library. Simply put, Church was getting tired of paying to re-laminate Barrow's previous restoration efforts. In 1965, thirty years after the introduction of the Barrow method of cellulose acetate lamination to conserve documents, Barrow noted that refinements in the process were still being made. ${ }^{8}$

As unlikely as it may seem to us today that collection care professionals would stick sheets of transparent plastic to historical documents, at the time this process was regarded as a best practice by conservators, some of whom considered it "the final answer" to the problem of strengthening and conserving documents. ${ }^{9}$

It is difficult to determine exactly how many repositories across the country were using the cellulose acetate lamination technique, but suffice it to say, many were. By the end of the 1980s Barrow's shop had sold at least 41 of his patented roller-type laminator machines to libraries and archives around the world, including the Library of Congress, Cuba, India, and countries in Europe. Domestically, Barrows' equipment was sold mostly in the southeastern United States, but records from Barrow's shop indicate that there were also commercial-service vendors using his machines, thereby making large-scale lamination services available to small repositories that

7. Barrow, "Deacidification and Lamination," 287. Evidently there may have been some continued experimentation without the plasticizer because his 1965 article on the cellulose acetate lamination process, Gear suggested that laminating with "unplasticized" laminate was undesirable because the films were not "heat sealable at a temperature suitable for paper records" and "thus plasticizers were incorporated into them to lower their softening points." (Gear, "Lamination After 30 Years," 294, 295) In a small bit of irony, in 1957 Robert W. S. Turner wrote, "Microfilm is virtually the same material as cellulose acetate foil but contains different plasticizers. There is no reason to suppose, provided the master negatives are properly stored and periodically inspected, that the information on film could not be preserved thousands of years." Robert W. S. Turner, "To Repair or Despair?," American Archivist 20, no. 4 (October 1957): 321; "Cellulose Acetate Lamination," 55.

8. Roggia, "The Great Promoter," 33; Barrow, "Deacidification and Lamination," 287-288.

9. Hummel and Barrow, "Lamination and Other Methods," 260-261, 263. 
might not have had the means to purchase the equipment themselves. Additionally, Barrow's lamination process was not the only one being employed during this time. The National Archives used a steam-heated flatbed hydraulic press to adhere the thermoplastic to the documents, and it is probable that other institutions used similar or more improvised heating and pressing processes for lamination. ${ }^{10}$

It was only in the 1970s that popular opinion began to turn against the cellulose acetate lamination process. In 1973, the National Archives acknowledged that they were in the midst of an "in-depth study of substitutes for the lamination process," noting that there was "evidence that this process is not without some harmful effects." Three years later, Frazer G. Poole, assistant Director for Preservation at the Library of Congress, wrote that cellulose acetate lamination was being phased out, "in favor of techniques which are much less damaging to the originals and which leave them completely accessible for future treatments if needed." Even with those notable critiques, however, there were holdouts and the practice continued, albeit limitedly, until it was finally put out of its misery in the late 1980 s. $^{11}$

By then many documents had been conserved using the cellulose acetate lamination process. In the summer of 2014, the Heritage Science for Conservation Program with the Department of Conservation \& Preservation with the Sheridan Libraries at Johns Hopkins University conducted a survey of 89 institutions which included federal, state, county, local, and private libraries, archives, and museums. They ranged from small to large and included at least one from every state. Of the 52 who responded, $74 \%$ confirmed that they held laminated documents within their collections, and of those, $65 \%$ specified that they held cellulose acetate laminated items (as opposed to modern or other laminate types). Two of the institutions surveyed indicated that they each had over one million cellulose acetate laminated documents, and the final report indicated that there were at least 2.9 million cellulose acetate laminated documents housed in collections across the country. ${ }^{12}$

10. Sally Cruz Roggia, "The Great Promoter: William J. Barrow and His Role in the History of Conservation," Book and Paper Group Annual 20 (2001): 32; McGath, et al., "Cellulose Acetate Lamination,” 339.

11. "Technical Notes," American Archivist 36, no. 1 (January 1973): 84; Frazer G. Poole, "Current Lamination Policies of the Library of Congress," American Archivist 39, no. 2 (April 1976): 157-159; In a 1987 article, Roger Jones from the North Carolina State Archives wrote that he considered the 1976 Poole article to be the death knell for cellulose acetate lamination. Roger Jones, "Barrow Lamination: The North Carolina State Archives Experience," American Archivist 50, no. 3 (Summer 1987): 390-396; Roggia has suggested that it was a 1959 National Bureau of Standards study that precipitated the decline in the popularity of the cellulose acetate lamination process. The report indicated that some laminated documents tested were showing a rapid deterioration. Roggia, "The Great Promoter," 33.

12. McGath, et al., "Cellulose Acetate Lamination," 350; According to the survey, the most common laminate identified was cellulose acetate lamination "with heat and pressure, either with tissue (58.3\%) or without (25\%). Other responses included Morane/Ultraphan Process (cellulose acetate film bonded using a heat-sensitive adhesive, $8.3 \%$ ), Mylar-polyethylene composites (4.2\%), Postlip Duplex laminated tissue (4.2\%), Polythene (4.2\%), and soluble nylon (4.2\%). Three other options given on the survey, the Goel Process (Goel 1953), Mipofolie process, and Sundexing (Darlington 1955), were not chosen by any of the respondents." Ibid., 354. 
Nonetheless, the authors of the report admit that these numbers are probably way too low. In a 1987 article, Roger Jones from the North Carolina State Archives (now the State Archives of North Carolina) indicated that his repository alone held an estimated two million laminated documents. According to the survey's authors, the Library of Congress, which had at least two laminating machines, indicated that in a single year that institution laminated 90,000 documents and 20,000 maps. The Delaware State Archives laminated 5,000 documents in the first year that they had their machine, so with that number, "given as a minimum, the total for the 25 years from their first use," would be 125,000 documents. After 50 years of laminating and knowing an average use of 11,000 documents in one fiscal year, the report projected that the Maryland State Archives using one laminating machine had, "a low estimate" of 500,000 laminated documents. The South Carolina State Archive was averaging 65,000 documents per year in the 1970s and probably accumulated around 650,000 laminated documents in that decade. And the report cited another article indicating that the Pennsylvania State Archives had laminated 144,000 land surveys alone. "Using only these estimates and documented numbers, the total number of laminated documents exceeds 3.5 million." Furthermore, that figure does not even include the National Archives, which began laminating in the 1930s and by 1965 had three laminating machines. According to the authors of the report, determining the number of laminated documents at the National Archives is difficult, but suffice it to say, it is "huge." These figures, of course, only document the institutions that were contacted and responded for the survey. ${ }^{13}$

Today conservators acknowledge that the main flaw in the lamination process was that the cellulose acetate foil itself was unstable at ambient temperatures and humidity. That is, it naturally deteriorated or degraded over time. Of greatest concern to librarians and archivists both today and in the future is the fact that this deterioration occurs at various levels and over varying amounts of time, especially when it is combined with a number of other factors. As a result, there is no predictable way to determine when or how laminated documents will weaken, fail, or eventually become unsalvageable.

The Johns Hopkins survey also asked each institution to indicate the overall condition of their cellulose acetate laminated documents. According to the authors, $76 \%$ deemed the condition of their laminated documents to be "mostly good" or "somewhat good." By the authors own admission, however, these results could be flawed for two reasons. First, they were concerned that the rating of "good" condition can mask the inherent degradation that is present, "though not visible," and which ultimately occurs. Second, "It is also possible that there may be a bias in

13. McGath, et al., "Cellulose Acetate Lamination," 350-351; Jones, "The North Carolina State Archives Experience,” 394. 

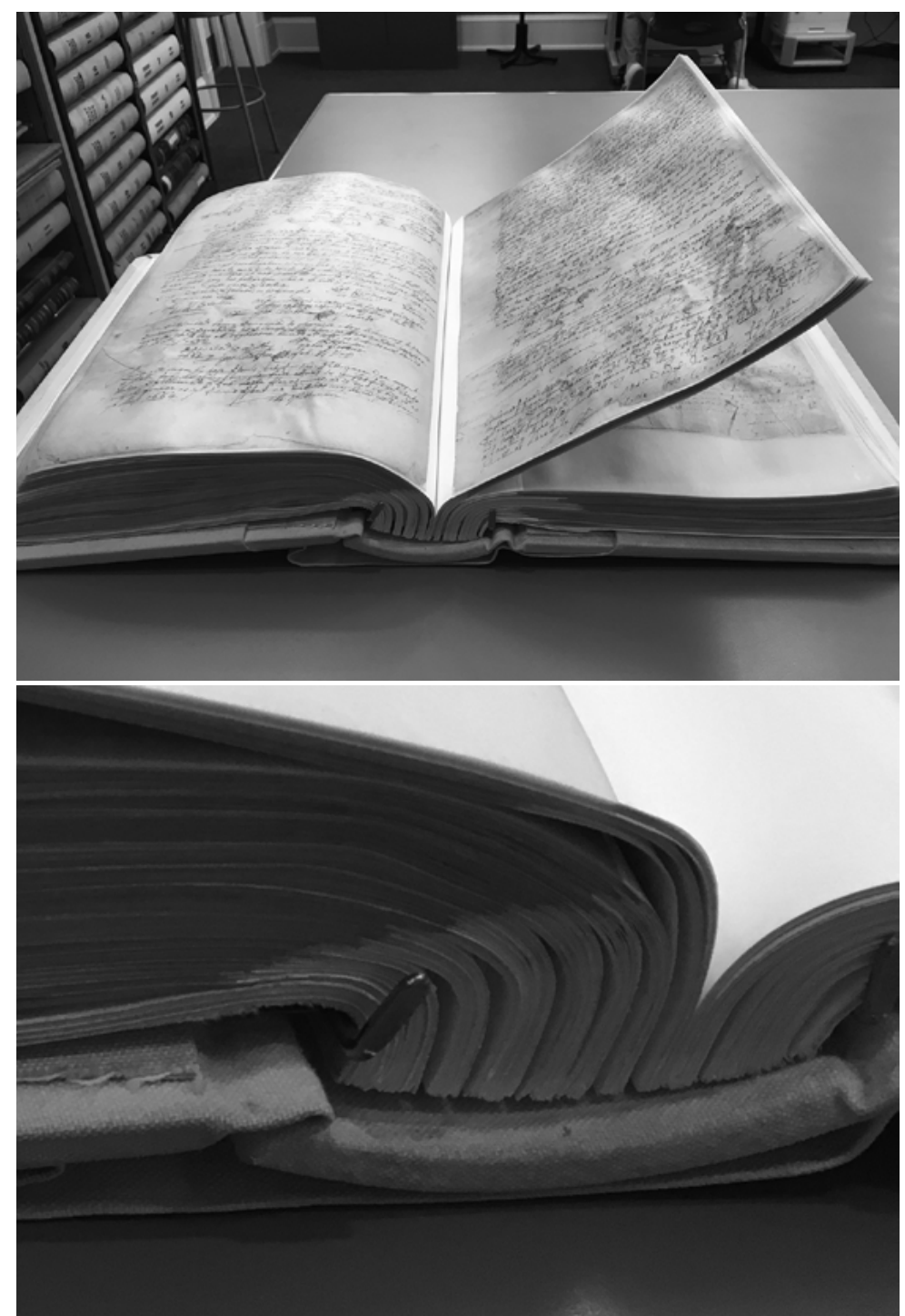

ILLUSTRATION 4-5. A laminated 17th century deed book. Detail image shows the spine of the inflexible post binding common to large volumes of laminated materials. (Circuit Court Records Preservation Program, Library of Virginia; photos by the author)

these assessments in that the removal of the poorest laminates may have prompted an overly positive view of the treatment," and of the documents that remain. However, there could be another factor that plays into their overly optimistic outlook on the situation: if respondents were to admit that their documents were failing or degrading, then they would have to address the delamination issue. Simply put, some of these repositories had so much invested in the cellulose acetate lamination process, than that to admit that they had a problem would be to admit that 
their documents were degrading and they would have to find a solution to stop the deterioration and destruction of their documents. ${ }^{14}$

What has since become clear is that in order to save these items, the lamination must be removed. Delaminating documents is not easy. It is time consuming and expensive, and there are circumstances where conservators believe that some documents have deteriorated too much to be saved. In other words, the cellulose acetate laminate cannot be removed without damaging the document even more. The process of removing the laminate is complicated on a number of levels and because of the various factors that contribute to the deterioration of the documents. Because of the numerous impediments to delamination, the respondents to the Johns Hopkins survey indicated that, of the millions of laminated documents reported, only 16,100 or $0.6 \%$ had been delaminated..$^{15}$

\section{The Symptoms}

With what we know now, and even with what we knew then, how did so many professional conservators, librarians, and archivists get swept away with the cellulose acetate lamination craze? In 1964, James L. Gear, Chief Chemist with the Document Restoration Branch at the National Archives admitted that information about how the idea of melting cellulose acetate foil to historical documents originated was "altogether hazy" to him. Lamination may have been popular partially because of the systematic, almost assembly-line process that made it attractive as a quick, efficient, and inexpensive alternative to traditional conservation techniques, especially when dealing with massive quantities of documents. Or it may have been the idea that the process was supposed to have been easily reversible, with what Gear termed as, "its easy removal at room temperature with solvents that do not harm paper," a claim which we now know to be false. ${ }^{16}$

Deputy Librarian of Congress Verner Clapp, a supporter of the cellulose acetate lamination process and a proponent of Barrow and his work, wrote in 1942 that the

\footnotetext{
14. McGath, et al., "Cellulose Acetate Lamination," 354.

15. In 1976, Frazer Poole acknowledged that delamination was difficult and sometimes the laminate could not be removed from the documents. Poole, "Current Lamination Policies," 157; As the cellulose acetate "laminate film loses acetyl groups due to hydrolysis, it becomes progressively less soluble in acetone, and more difficult to separate from the paper. The implication would be that when a CA laminated document is at risk of hydrolysis because it is acidic or exposed to high humidity, there may be a limited time in which reversal of the lamination is feasible, and there may not be visible clues that this hydrolysis has occurred." McGath, et al., "Cellulose Acetate Lamination," 348-349, 356.

16. Gear, "Lamination After 30 Years," 293, 296; Baker, Double Fold, 148-149; McGath, et al., "Cellulose Acetate Lamination," 338, 349. In his defense of the Barrow method, a former staff member who worked with Barrow in his restoration shop in the Virginia State Library in the 1950s touted the ability to incorporate several related documents of different sizes into one "larger laminated sheet" which could be assembled into a "bound and organized form" facilitating their use by researchers. John A. Church, "William J. Barrow: A Remembrance and Appreciation," American Archivist 67, no. 1 (Spring/ Summer 2004): 157.
} 
process had "withstood the test of time" and had become "the standard method." At least in some quarters, however, there appears to have always been questions regarding the process and in particular, the stability of the cellulose acetate film. This was even more markedly true when it came to the addition and consequences of the plasticizer. Many European experts, especially those in the UK, always viewed the process with some skepticism, asserting that it had not been sufficiently time tested. In 1956, T. R. Shellenberg, then at the National Archives, stated that, "After twenty years of experience with the lamination process[,] the National Archives has found this skepticism to be at least partially justified." A few years later, a study by the National Bureau of Standards demonstrated that some laminated documents were beginning to show rapid deterioration. Meanwhile, even as doubts were being raised, the National Archive was transitioning or upgrading their cellulose acetate lamination program, adding the tissue strengthening and deacidification of paper that Barrow began doing ten years previous. The confused and evolving standards, processes, or protocols led Robert W. S. Turner to write, "The present rough-and-ready, rule-of-thumb methods of repairing documents with cellulose acetate foil must inevitably lead to accidents and to the damaging of irreplaceable documents." ${ }^{17}$

The situation facing archives and special collections today is that the cellulose acetate laminated items in their collections were treated with various procedures over various time periods. As a result, with all of these tweaks and changes to the formula and processes there is no predictable or fixed way to determine how or at what rate a document will deteriorate. In general, the older laminated documents will be farther along in the process; however, varying environmental storage conditions can also have an adverse effect on the documents. In addition to the problems outlined with deacidification and plasticizers, other factors that could contribute to the unevenness of the deterioration might include the manufacturing quality or thickness of the cellulose acetate; whether tissue was used to reinforce or strengthen the paper, whether a heated roller or flat press was used; and ultimately the time, temperature, and pressure used in the heating process. Additionally, the differing heating and pressing processes could lead to differing future problems such as trapped pockets of moisture or air and/or trapped vaporized plasticizer. Because of the number of possible variables, one cannot simply establish or prioritize the treatment of the laminated documents by date, assuming that the oldest is in most need of treatment and working forward. ${ }^{18}$

17. Verner Clapp, "The Story of Permanent/Durable Book Paper, 1115-1970," Scholarly Publishing 2 (January 1971): 112; Turner, "To Repair or Despair?," 320-321, 326; D. L. Evans, "The Lamination Process: A British View,” American Archivist 9, no. 4 (October 1946): 320-322; T. R. Schellenberg, Modern Archives (Chicago: University of Chicago Press, 1956): 166; Roggia, "The Great Promoter," 33; Gear, "Lamination After 30 Years," 296.

18. Turner, “To Repair or Despair?,” 323-324; Munson, Guidelines. 
For the most part, documents that were not deacidified prior to lamination are the ones that show evidence of acid degradation and are turning yellow or brown. These documents were probably laminated during the first 20 or so years, while Barrow and others were learning more about paper composition and the detrimental effects of hermetically sealing or laminating the acids in the paper without any means of off-gassing. This means that instead of preserving the documents by laminating them, the lamination was sealing the acids in the paper and hastening the documents' deterioration. If documents in a collection were laminated before they were deacidified, they should be top candidates for delamination. Deacidification itself is a huge variable though. While the Barrow Restoration Lab at the Virginia State Library began deacidifying before laminating in the early 1940s, the National Archives did not begin routinely deacidifying documents prior to lamination until 1957. Even then, the quality of the deacidification process as well as the deacificiation solutions varied from shop to shop and conservator to conservator and, in the end, the process also turned out to be unreliable. ${ }^{19}$

To make matters worse, if written documents are old enough they might contain iron gall inks. Because these old writing inks were concocted as needed by the person using them, the concentration of iron particles in an ink batch and therefore the acidity levels added to the paper vary from document to document. The problems produced by the iron gall ink become most noticeable in areas of high concentration. The results of iron-gall acidity on paper can usually be seen in the fanciful or elaborate flourishes in the capital letters at the beginning of a document, heading, or paragraph. On their own, even without lamination, such concentrations of ink can cause areas of loss; however, each time these documents are delaminated these swaths of ink are often further weakened or removed, sometimes taking portions of the document with them..$^{20}$

What appears to be the most common problem with laminated documents today results from the addition of the plasticizer to the cellulose acetate film to give it more strength and flexibility. As previously stated, when the plasticizer evaporates or dries up the laminate turns stiff and the documents can begin to shrink, warp,

19. Gear, "Lamination After 30 Years,” 296; Poole, "Current Lamination Policies,” 158. The Library of Virginia still has county court record books from the 1930s that were custom bound in wood boards which appear to be accelerating the deterioration of the cellulose acetate laminated pages that were never deacidified.

20. Page, "Cellulose Acetate Lamination," 56. There were many variables involved in the ink making process, however, by the $17^{\text {th }}$ century much of the ink used was purchased in a powder form with a liquid, usually water, added by the user. William J. Barrow, "Black Writing Ink of the Colonial Period," American Archivist 11, no. 4 (October 1948): 297-298, 299, 304; Martha Woodroof Hiden, "Virginia County Court Records," Register of Kentucky State Historical Society 38, no. 125 (October 1940): 361. 
bubble, split, and/or crack. In bound volumes, the rigid pages begin to tear at the gutter, separating them from the book's spine. ${ }^{21}$

\section{Is There A Cure?}

Many things factor into the delamination process and can affect whether it is successful or not. This includes the state or stage of the decomposition of the cellulose acetate lamination itself as it changes over time. Because delamination involves immersing the laminated pages into a chemical solvent to remove the cellulose acetate film, usually acetone or acetone and water, the process has detrimental effects on the integrity of the document. This proves to be especially problematic if the document has already been delaminated before, weakening the inherent strength in the paper.

The inevitable result of so many interacting conditions and variables is that repositories find themselves with documents laminated in various eras and in various states of deterioration, with no definite correlation between when they were laminated and their current condition. Documents laminated in the 1930s might appear to be fine, while others are discolored yellow or brown. They can emit the vinegar smell (or "vinegar syndrome") associated with the degradation of cellulose acetate film, or they might have absolutely no odor at all. The laminated documents may have deteriorated to a translucent state, with the writing or printing on the opposite side of the document now visible through the sheet, or the surface could be as legible and clear as if it were brand new. The documents might be bubbling, shriveling, cracking, or warping, or not. In some instances or under certain conditions, the laminated pages could begin to stick together. These inconsistencies and the unpredictability of deterioration makes a systematic approach to delamination difficult; as a result, each document needs to be evaluated on a case by case basis in order to determine its condition and where it should fall within the delamination queue. This proves to be especially troublesome when a repository has hundreds, thousands, or millions of such deteriorating documents. ${ }^{22}$

Despite the mounting evidence against lamination, a few holdouts continued to advocate for the process well into the 1980s as an alternative to what was perceived as a new or modern "fine arts" method of document conservation being taught at the time. In his 1987 essay, Roger Jones seemed to pitch cellulose acetate lamination as the low cost alternative for "preserving huge quantities of deteriorating paper records," thereby saving the documents of "great historical significance"

21. The Johns Hopkins survey indicated that the most prevalent forms of deterioration were cracking $(58.8 \%)$ and darkening of the paper $(58.8 \%)$, followed by bubbling of the film $(47.1 \%)$, delamination of the film and/or tissue (47.1\%), breaking (35.3\%), discoloration (35.3\%), paper curling or changing shape (35.3\%), and vinegar odor (29.4\%). McGath, et al., "Cellulose Acetate Lamination," 354.

22. Munson, Guidelines; Page, "Cellulose Acetate Lamination," 55. 
or "high monetary value" for the conservators with their new artisan-style "hand craft" techniques. With this approach, Jones appeared to be suggesting that cellulose acetate lamination was appropriate for common historical documents because no archives could afford the modern methods for a large conservation program; and that the conservation of important historical documents would be reserved for the hand craft technique. The implied reasoning was that individual, document by document treatment by conservators would be too costly for most repositories. Of course, the unfortunate irony is that today the only way to actually save the documents is to remove the lamination by employing the expensive hand craft document by document restoration approach that Jones was trying to avoid. ${ }^{23}$

\section{Prognosis Negative}

Jane Smith, a conservator who spent three years delaminating documents in the Pennsylvania State Archives, stated that even when the documents look fine, they have been, "inherently changed, because you've just melted plastic into the interstices of the paper, so you do not have a piece of paper anymore. You've introduced thermal oxidation and heavy pressure, and you've just filled all of the pores of the paper with melted plastic...." Smith likened the look of a cellulose acetate laminated document to a plastic dinner placemat. ${ }^{24}$

To aggravate the complexity of the problem, in the worst-case scenarios many of the negative factors outlined above compound one another, forming something of a critical mass that makes safe delamination of these documents impossible or unwise because of the further damage that such serious intervention might cause to the item. The fact that delamination is an expensive process that can only be performed by trained conservators makes determining which documents should be rescued from lamination all the more problematic. With funding at a premium, archivists and librarians must make decisions on how to proceed with their repository's conservation strategy. Again, the varying conditions of these laminated documents make this even more difficult. Should we send our most deteriorated documents to the conservation lab knowing that their treatment might be more expensive? Or that they might even be unsalvageable? The unfortunate fact is that the items that are the most degraded are typically some of the oldest and most historically significant documents in the collection; they were previously prioritized for lamination because of their age, rarity, and value to the collection. In other

23. Supporting his thesis, Jones cited Howard Lowell, State Archivist of Oklahoma, who had similar views regarding the upstart hand craft conservation methods. Jones, "The North Carolina State Archives Experience," 396.

24. Baker, Double Fold, 150; McGath, et al., "Cellulose Acetate Lamination,” 347. The Smithsonian Institution's Anthropology Conservation Laboratory pamphlet, Guidelines for the Care of Works on Paper with Cellulose Acetate Lamination, supports Smith in that, "the lamination process drives the plastic laminate into the paper itself." Munson, Guidelines. 
words, some of the most historical and valuable documents in the collection might be the ones most in need of conservation, but now might be either too extensively deteriorated or on the verge of becoming unsalvageable.

On the other hand, should we concentrate our efforts on the laminated documents that appear to show the least amount of deterioration so as to be more easily recovered? All things being equal, archivists and special collections librarians might be inclined to want the older documents saved. But, as with the cellulose acetate lamination process itself, all things are not equal. So, we are put in the unenviable position of deciding if we should spend our money on the more costly, heavily deteriorated documents that are possibly of more historical value, but might not be salvageable, or to opt for the more easily treated documents, knowing we can save them? If we select the later solution, we are faced with imaging the older documents and awaiting their destruction.

Unfortunately, this is an article addressing a problem without a straightforward answer or solution. Just as institutions once budgeted to fund lamination as a preservation measure, institutions must now budget to fund delaminating material—as a preservation measure.

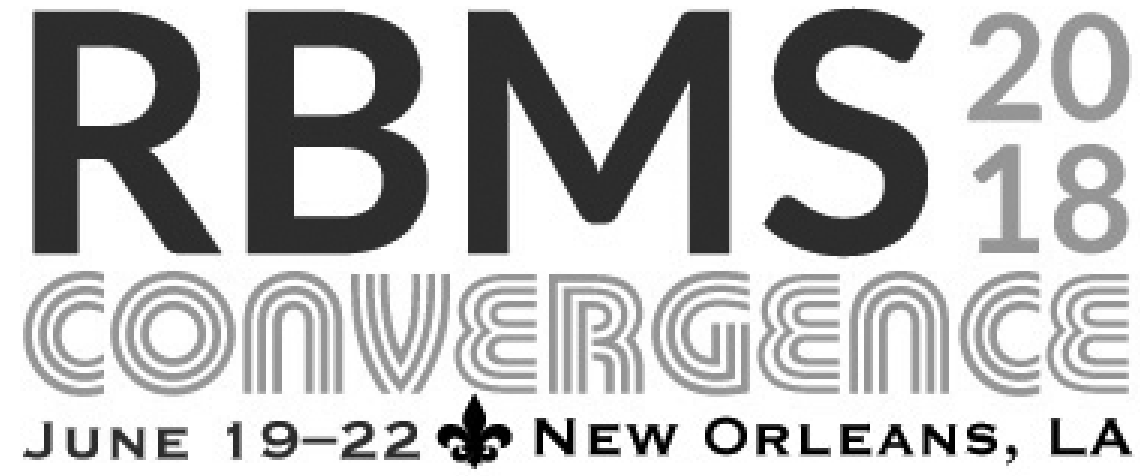

\section{REGISTRATION OPENS IN FEBRUARY. SCHOLARSHIPS AVAILABLE.}

\section{conference.rbms.info/2018}

